\title{
Approach to leg edema
}

Fulvio Pomero, ${ }^{1}$ Roberta Re, ${ }^{2}$ Michele Meschi, ${ }^{3}$ Domenico Montemurro, ${ }^{4}$ Laura Spadafora, ${ }^{5}$ Valentina Borretta, ${ }^{5}$ Monica Zampogna, ${ }^{6}$ Annalisa Marchetti, ${ }^{7}$ Mariangela Di Lillo, ${ }^{8}$ Daniela Tirotta,,${ }^{9}$ Chiara Bozzano, ${ }^{10}$

Micaela La Regina, ${ }^{11}$ Paola Gnerre ${ }^{12}$

${ }^{1}$ Internal Medicine Department, S. Croce e Carle Hospital, Cuneo; ${ }^{2}$ Internal Medicine Department, Maggiore della Carità Hospital, Novara; ${ }^{3}$ Internal Medicine Department, Santa Maria Hospital, Parma; ${ }^{4}$ Internal Medicine Department, S. Bortolo Hospital, Vicenza; ${ }^{5}$ Specialty training in Internal Medicine, University of Turin; ${ }^{6}$ Specialty training in Nutrition, University of Padova; ${ }^{7}$ Accident and Emergency Department, INRCA, Ancona; ${ }^{8}$ Accident and Emergency Department, Ospedali Riuniti, Marche Nord, Fano (PU); ${ }^{9}$ Internal Medicine Department, Hospital of Cattolica (RN); ${ }^{10}$ Accidents and Emergency Department, San Donato Hospital, USL 8, Arezzo; ${ }^{11}$ Internal Medicine Department, Levante Ligure Hospital, ASL 5, La Spezia; ${ }^{12}$ Internal Medicine Department, San Paolo Hospital, Savona, Italy

\begin{abstract}
Edema is defined as a palpable swelling caused by an increase in interstitial fluid volume. Leg edema is a common problem with a wide range of possible causes and is the result of an imbalance in the filtration system between the capillary and interstitial spaces. Major causes of edema include venous obstruction, increased capillary permeability and increased plasma volume secondary to sodium and water retention. In both hospital and general practice, the patient with a swollen leg presents a common dilemma in diagnosis and treatment. The cause may be trivial or life-threatening and it is often difficult to determine the clinical pathway. The diagnosis can be narrowed by categorizing the edema according to its duration, distribution (unilateral or bilateral) and accompanying symptoms. This work provides clinically oriented recommendations for the management of leg edema in adults.
\end{abstract}

\section{Introduction}

Edema is defined as a palpable swelling due to an increase of fluid volume in the interstitial space. The management of a patient with edema should be based on epidemiology, past medical history and physical examination, as shown in the flow chart (Figure 1), in order to clarify the etiology and the diagnosis. Furthermore, advice and criteria should be proposed to stratify the clinical risk and guide the decision to hospitalize. ${ }^{1,2}$

Correspondence: Fulvio Pomero, Internal Medicine Department, S. Croce e Carle Hospital, via Coppino 26, 12100 Cuneo, Italy.

Tel.: +39.0171642030 - Fax: +39.0171642075

E-mail: fulviopomero@yahoo.it

Key words: Edema; internal medicine; differential diagnosis.

Conflict of interest: the authors declare no potential conflict of interest.

Received for publication: 27 August 2016.

Revision received: 20 December 2016

Accepted for publication: 3 January 2017.

This work is licensed under a Creative Commons Attribution NonCommercial 4.0 License (CC BY-NC 4.0).

CCopyright F. Pomero et al., 2017

Licensee PAGEPress, Italy

Italian Journal of Medicine 2017; 11:267-277

doi:10.4081/itjm.2017.771

\section{Physiopathology}

Fluid retention could be determined both by a capillary leak with fluid translocation to the interstitial space and renal re-absorption of water and sodium (either introduced by oral intake or infusion), causing an endocrine mechanism of salt retention.

Nevertheless, if the pathogenesis of the edema is primarily due to hydro-saline retention, the fluid overload tends to be both intra and extra-vascular (the socalled overfilling, typical of primary nephropathies). ${ }^{3,4}$

\section{Pathogenesis}

The fluid movement across the capillary membrane is the result of a balance between hydrostatic and oncotic pressure, according to the Starling equation:

$A=B C(\Delta D-\Delta E)=B C[(F-G)-(H-I) L]$

where: $A$ is the net filtration (total fluid movement); $B$ is the permeability coefficient (porosity); $C$ is the capillary surface area; $D$ is the hydrostatic pressure; $E$ is the oncotic pressure; $F$ is the capillary hydrostatic pressure; $G$ is the interstitial hydrostatic pressure; $H$ is the capillary oncotic pressure; $I$ is the interstitial oncotic pressure; $L$ is the reflection coefficient (depends on permeability to protein: $0=$ free permeability, $1=$ complete non permeability).

As a consequence, edema can be secondary to: ${ }^{5}$ 
- $\quad$ Altered fluid balance: edema occurs when the filtration gradient is increased to at least $15 \mathrm{mmHg}$, as demonstrated in most clinical and laboratory settings. ${ }^{6}$

- Role of hydro-saline retention mechanisms (activation of RAA, ADH and sympathetic nervous system): hydro-saline retention should be considered in many cases as a compensatory response to volume depletion but sometimes can be related to primary renal dysfunction. The complexity of these endocrine interactions is well described in some pathologic conditions, such as liver and heart failure..$^{7-11}$

- Increased pulmonary capillary hydrostatic pressure: this condition could be determined by a circulatory fluid overload (heart and/or renal failure), partial or complete venous obstruction (deep vein thrombosis, liver cirrhosis). ${ }^{12-15}$

- Reduced capillary oncotic pressure: capillary oncotic pressure is reduced in all cases of hypoproteinemia and/or dysproteinemia, such as urinary protein loss and impaired protein synthesis in chronic liver diseases. ${ }^{12-15}$

- Increased capillary permeability: this is the case of skin burns, therapy with interleuchin-2 recombinant protein or other endothelial vascular growth factors, circulating cytokines abnormalities as in adult respiratory distress syndrome and severe malnutrition. ${ }^{12-15}$

\section{Etiology}

\section{Venous (or lymphatic) drainage obstruction}

In these conditions, the hydrostatic pressure raises in the capillary segment above the obstruction. Therefore, fluids move from vascular to extra-vascular space.

Examples are thrombophlebitis and deep vein thrombosis. In the venous insufficiency, the underlying mechanism is the same, with increased fluid translocation to interstitial space as a consequence of venous stasis and increased pressures.

Reflex sympathetic dystrophy (RSD) should be suspected when leg edema is associated with pain. Lymphedema could be secondary to pelvic malignancy, infections, radiotherapy, lymph nodes excisions. In contrast, primary edema is a rare condition and may be congenital, early and hereditary.

\section{Inflammatory edema}

This condition is determined by an increase of vascular permeability to plasmatic proteins. It may

\section{EDEMA}

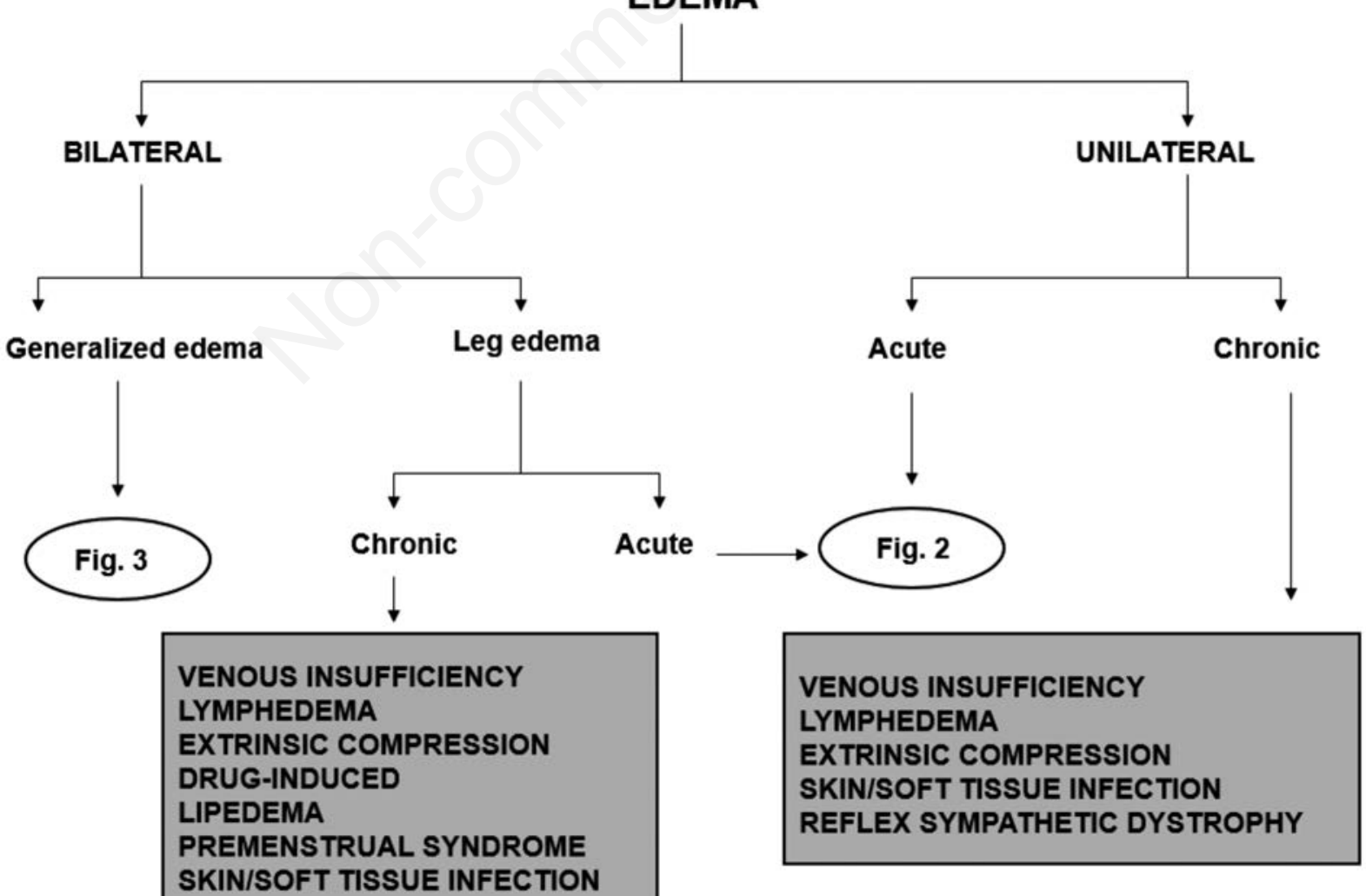

Figure 1. Edema. 
be secondary to several inflammatory processes localized to the legs, such as infections, chemical substances, mechanic or traumatic agents or immunological factors.

\section{Pulmonary hypertension}

There are several causes of pulmonary hypertension (heart failure, chronic lung diseases, etc.); however, the pathogenesis of edema is always related to an impaired right ventricular output leading to an increase in right ventricular diastolic pressure and fluid movement to the interstitial space.

\section{Other causes of hypoproteinemia}

Other causes of hypoalbuminemia are severe malnutrition (including eating disorders), protein losing enteropathies, malabsorption.

\section{Endocrine, hormonal and gynecologic causes}

Edema may be caused by several endocrine alterations, among which increased levels of glucocorticoids and mineralocorticoids (hydro-saline retention), thyroid dysfunction (vascular dysfunction in hyperthyroidism causing pretibial edema, while myxedema in hypothyroidism is mainly due to accumulation of glycosaminoglycan in the dermis), ovarian hyper- stimulation syndrome (in vitro fertilization), obesity (association with venous insufficiency, lymphedema, obstructive sleep apnea syndrome, and idiopathic edema). Hormonal factors are responsible of premenstrual and pregnancy edema, as well as in pre-eclampsia.

\section{Drug-induced edema}

Several drugs can potentially lead to edema through different mechanisms (renal vasoconstriction, arteriolar dilation, capillary damage, sodium reabsorption, etc.).

\section{Idiopathic edema}

This syndrome affects almost only women, in particular in the second and third decades; it is characterized by periodic edema without any association with the menstrual cycle.

\section{Diagnosis}

Venous insufficiency is the most common cause of peripheral edema in people aged $>50$ years, while in women $<50$ years the etiology is often idiopathic. ${ }^{2}$

\section{Epidemiology}

The accurate prevalence of different etiologies, is not definitely stated in the literature. However, we di- vided all causes in common, less common and rare (Table 1).

\section{Medical history}

Past medical history and presenting complains are very useful to guide the diagnosis, in particular: i) presenting symptoms/duration; ii) pain; iii) concomitant medical conditions; iv) past medical history of surgery, radiotherapy, pelvic cancers; v) medications (Table 2).

\section{Physical examination}

Physical examination is extremely relevant to collect information and formulate the differential diagnosis. For this purpose, it is important to assess (Table 3): i) edema distribution; ii) pitting features; iii) skin changes; iv) measurement of venous pressure; v) signs of localized diseases; vi) signs of systemic diseases; vii) signs of pelvic obstruction.

\section{Laboratory tests}

Firstly, common laboratory tests could be useful to detect systemic diseases (full blood count + leukocytes formula, electrolytes, creatinine, glycemia, albumin, thyroid functioning tests, urine exam); subsequently, second-line tests should be performed, depending on the clinical suspicion: i) deep vein thrombosis: D-dimer; ii) heart failure: NTproBNP; iii) liver failure: alanine transaminase, aspartate aminotransferase, total and fractioned bilirubin, haptoglobin, prothrombin time, plasmatic albumin; iv) renal failure: complete urine analysis (sediment, $24 \mathrm{~h}$ proteinuria), lipids profile.

\section{Other diagnostic tests}

Depending on the most likely diagnosis (Figure 1), further diagnostic tests are advised.

\section{Venous insufficiency edema}

\section{Deep vein thrombosis}

Deep vein thrombosis (DVT) is one of the most common cause of peripheral edema.

Usually it affects only one side, but rarely might be bilateral. A DVT presents with leg edema in $90 \%$ of the patients, while pain and redness are not demonstrated to be positive predictors. In contrast, increased temperature in the affected leg $\left(>37.5^{\circ} \mathrm{C}\right)$ has shown to be a negative predictor of DVT (odds ratio 0.34; $\mathrm{P}=0.003) .{ }^{16}$ Probability of DVT is also related to risk factors, such as cancer [likelihood ratio $(\mathrm{LR})=2.71$ ], previous episode of DVT $(\mathrm{LR}=2.25)$, reduced mobility $(\mathrm{LR}=1.98)$, recent surgery $(\mathrm{LR}=1.76) \cdot{ }^{17}$ Although 
Table 1. Common, less common and rare causes of peripheral edema.

\begin{tabular}{|c|c|c|c|}
\hline \multicolumn{2}{|l|}{ Unilateral } & \multicolumn{2}{|c|}{ Bilateral } \\
\hline Acute & Chronic & Acute & Chronic \\
\hline \multicolumn{4}{|c|}{ Common causes } \\
\hline Deep vein thrombosis & Venous insufficiency & & $\begin{array}{l}\text { Venous insufficiency } \\
\text { Pulmonary hypertension } \\
\text { Heart failure } \\
\text { Idiopathic edema } \\
\text { Lymphedema } \\
\text { Medications } \\
\text { Premenstrual edema } \\
\text { Pregnancy } \\
\text { Obesity }\end{array}$ \\
\hline \multicolumn{4}{|c|}{ Less common causes } \\
\hline Baker's cyst rupture & $\begin{array}{l}\text { Secondary lymphedema } \\
\text { (malignancy, radiation, } \\
\text { surgery, infection) }\end{array}$ & Bilateral deep vein thrombosis & $\begin{array}{c}\text { Renal disease (nephrotic syndrome, } \\
\text { glomerulonephritis) }\end{array}$ \\
\hline $\begin{array}{l}\text { Fracture of the medial } \\
\text { head of the gastrocnemius } \\
\text { muscle }\end{array}$ & $\begin{array}{l}\text { Pelvic cancer/lymphoma } \\
\text { Causing vein obstruction }\end{array}$ & & Liver disease \\
\hline Compartmental syndrome & Reflex sympathetic dystrophy & & $\begin{array}{c}\text { Secondary lymphedema } \\
\text { (malignancy, radiation, infection, } \\
\text { filariasis) } \\
\text { Diuretic-induced edema } \\
\text { Pre-eclampsia } \\
\text { Lipedema }\end{array}$ \\
\hline \multicolumn{4}{|c|}{ Rare causes } \\
\hline $\begin{array}{r}\mathrm{Co} \\
\text { May-Tl }\end{array}$ & $\begin{array}{l}\text { Primary lymphedema } \\
\text { (congenital, early, late-onset) } \\
\text { genital arteriovenous malformation } \\
\text { urner syndrome (iliac vein compression) }\end{array}$ & & $\begin{array}{l}\text { Protein-losing enteropathy, } \\
\text { malnutrition, malabsorption } \\
\text { Constrictive pericarditis } \\
\text { Myxedema }\end{array}$ \\
\hline
\end{tabular}

Table 2. Drugs causing edema.

\begin{tabular}{ll}
\hline Hormones & Cytokines \\
\hline Estrogen & (IFN) $\alpha$ \\
$\begin{array}{l}\text { Testosterone } \\
\text { Steroids }\end{array}$ & IL-4, IL-2 \\
$\begin{array}{l}\text { Progesterone } \\
\text { Androgen }\end{array}$ & \\
\hline Antihypertensive drugs & Chemotherapy drugs \\
\hline Guanethidine & Cyclophosphamide \\
$\beta$-blockers & Cyclosporine \\
Calcium channel blockers (DHP and non-DHP) & Mitomycin \\
Clonidine & \\
Hydralazine & \\
Methyldopa & \\
Minoxidil & \\
Reserpine & \\
Labetalol & \\
\hline Antiviral drugs & \\
\hline Acyclovir & Antidiabetic drugs \\
\hline Non-steroidal anti-inflammatory drugs & Rosiglitazone \\
\hline & Pioglitazone \\
\hline & Antidepressants \\
\hline & Trazodone \\
\hline
\end{tabular}


a single clinical factor cannot accurately predict the diagnosis of DVT, the complete clinical history (summarized in the Wells score) should be used to predict the pre-test probability (Table 4). ${ }^{18} \mathrm{D}$-dimer positivity increases the probability of DVT independently from the clinical risk group, but is not diagnostic. ${ }^{19}$ However, D-dimer does not rule out the diagnosis in patients with intermediate or high risk (respectively, the probability of DVT is $8.6 \%$ and $1 \%$ ), while in patients with low risk it allows to exclude the diagnosis without further investigations (Figure 2).${ }^{19}$ Patients at high risk should undergo a compressive venous ultrasound (CUS) as first line investigation. A positive result confirms the diagnosis, while a negative test has to be followed by a negative D-dimer and sometimes other tests (Figure 2) ${ }^{20}$ If the d-dimer is positive, either CUS should be repeated in 3-7 days or a phlebography. ${ }^{21}$

\section{Compression ultrasound: accuracy in Accidents and Emergency Room}

DVT is a common presentation complain in Accidents and Emergency Room (A\&E). Therefore, CUS is often performed by emergency healthcare professionals, in order to reduce the time to diagnosis. A systematic review ${ }^{22}$ compared a CUS performed in A\&E setting and an ultrasound performed by skilled operators, concluding that diagnostic accuracy of DVT does not significantly differ (sensibility $96.1 \%$; specificity $96.8 \%$ ).

\section{Hospitalization criteria}

A Cochrane review showed that recurrence of venous thromboembolism is lower if patients are treated at home (recurrence rate $0.61 ; \mathrm{P}=0.013$ ), without any

Table 3. Characteristics of lipedema, lymphedema and venous stasis.

\begin{tabular}{|c|c|c|c|}
\hline & Lipedema & Lymphedema & Venous stasis \\
\hline Onset & Puberty or soon after & Variable & $\begin{array}{l}\text { Intermediate-late onset, depending } \\
\text { on etiology }\end{array}$ \\
\hline Distribution & Bilateral and symmetric & Unilateral $(70 \%)$ & Unilateral o bilateral \\
\hline Pitting & No & Yes & Yes \\
\hline Skin & Normal & $\begin{array}{l}\text { Thickening, hyperkeratosis, } \\
\text { verrucous, derma fibrosis in } \\
\text { advanced stages }\end{array}$ & $\begin{array}{l}\text { Erosions (ulcerations), transudates, } \\
\text { excoriations }\end{array}$ \\
\hline Tissue consistency & Soft & Pasty edema & Very soft \\
\hline Sensation & Especially above the tibia & Very low & No \\
\hline Foot involvement & No & Yes & Yes \\
\hline Cellulitis & 10 & Yes, very often & Yes, often \\
\hline Ulcers & No & No & $\begin{array}{l}\text { Yes, very frequently around the } \\
\text { medial malleolus }\end{array}$ \\
\hline Leg raising changes the edema & No & $\begin{array}{l}\text { Some beneficial effects in the } \\
\text { early stages, very few or no } \\
\text { effects in the advanced stages }\end{array}$ & Yes, noticeable improvement \\
\hline
\end{tabular}

Table 4. Wells score.

\begin{tabular}{|c|c|}
\hline Malignancy (on treatment, treated in the last 6 months or palliative care) & 1 \\
\hline Paralysis, paresis or recent immobilization of the leg & 1 \\
\hline Bedridden recently ( $>4$ days) or major surgery in the last 4 weeks & 1 \\
\hline Entire leg swollen & 1 \\
\hline Calf swelling $>3 \mathrm{~cm}$ compared to the other leg & 1 \\
\hline Pitting edema, greater on the suspected side & 1 \\
\hline Collateral (non-varicose) superficial veins present & 1 \\
\hline Alternative diagnosis to deep vein thrombosis as likely or more likely & -2 \\
\hline $\begin{array}{l}\text { - High risk }=\text { score } \geq 3 \mathrm{pt} \\
\text { - Intermediate risk }=\text { score } 1-2 \mathrm{pt} \\
\text { - Low risk }=\text { score } \leq 0 \mathrm{pt}\end{array}$ & \\
\hline
\end{tabular}


differences in terms of mortality and/or bleeding. ${ }^{23}$ In particular, home treatment is safe and effective in patients with: ${ }^{21}$ i) not complicated DVT (if not: contraindications to anticoagulation therapy, history of heparin induced thrombocytopenia, iliac-femoral vein DVT/phlegmasia, pregnancy); ii) normal cardio-respiratory functional reserve; iii) not high risk of bleeding; iv) creatinine clearance $>30 \mathrm{~mL} / \mathrm{min}$.

\section{Chronic vein insufficiency}

Edema is one of the clinical presentation signs of venous insufficiency; other symptoms include pain, itching, feeling of heaviness in the legs, cramps (especially during the night), while the most common signs are varices, skin changes up to ulcerations. The swelling is typically worsened by the standing position (therefore, it is usually more severe in the evening. ${ }^{24}$

In 1994, it was established the CEAP system, ${ }^{25}$ in order to stage the disease in relation to clinical presentations (C), etiology (E), anatomic distribution (A) and physiopathology $(\mathrm{P})$.

Doppler-ultrasound may confirm the diagnosis and is useful to determine the anatomy of the reflux, the origin, the course and the re-entry point, in order to plan the surgery. In addition to this, ultrasound allows to differentiate the post-thrombotic syndrome with residual thrombotic material from primary venous insufficiency. ${ }^{26}$

Although CEAP system is an excellent classification method, it is not very handy to quantify the severity of the disease. In this regard, the Venous Clinical Severity Score was created in 2000, in order to assess the severity and compare the outcome of homogenous groups of patients. ${ }^{27}$

\section{Hospitalization criteria}

Hospitalization should be limited to patients with ulcer infection and complications, either local or systemic.

\section{Reflex sympathetic dystrophy}

Reflex sympathetic dystrophy should be investigated when leg edema is associated with pain. In fact, RSD is a chronic neurologic disorder affecting the extremities and causing severe disability. It is usually preceded by a trigger (trauma, upper or lower extremities surgery, malignancy, pregnancy, osteogenesis imperfecta), even though the symptoms are disproportionately severe and can affect more than one innervation territory of a peripheral nerve. ${ }^{28}$

There are several stages of the disease: acute or warm, intermediate or dystrophic end-stage or

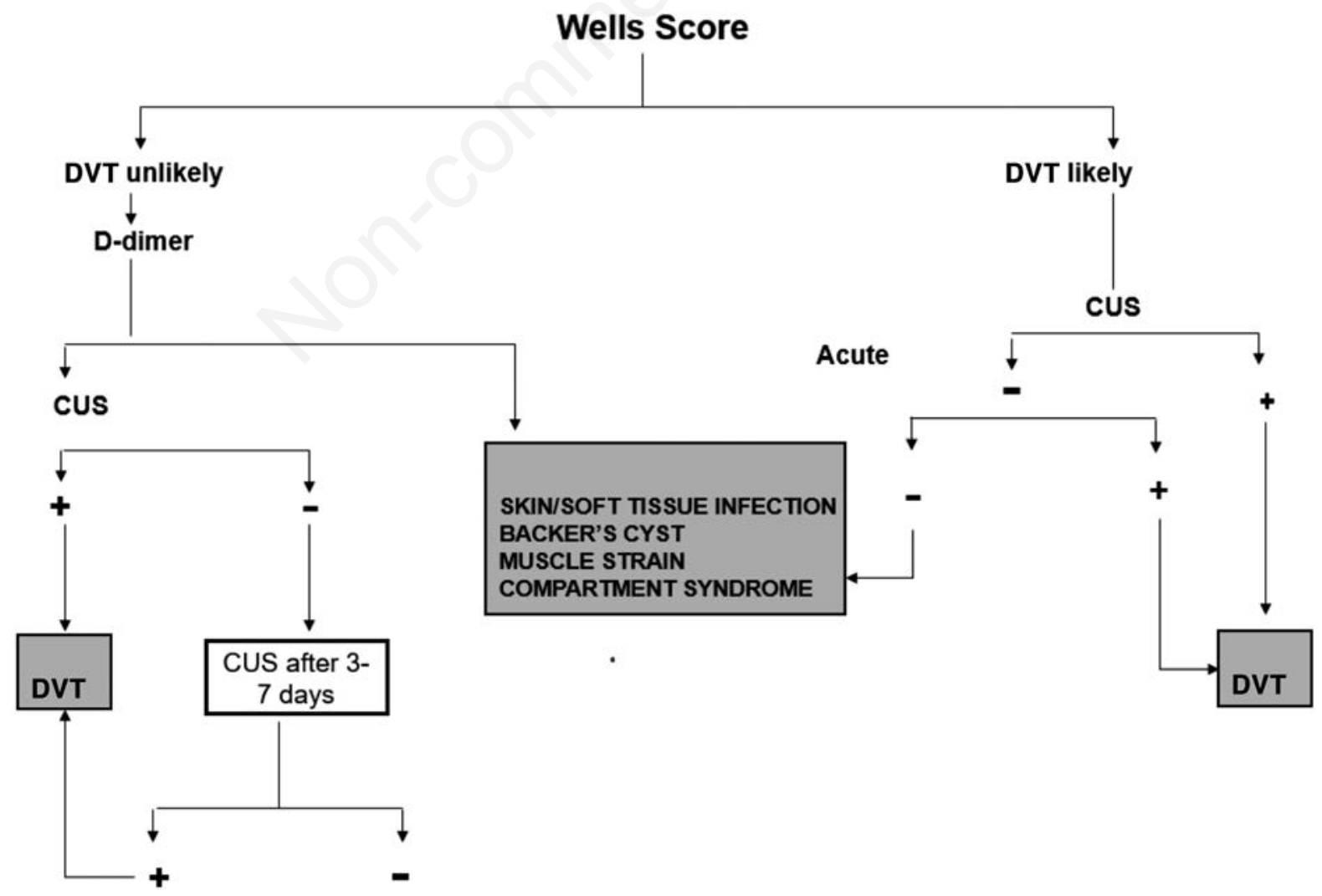

Figure 2. Approach to unilateral edema. DVT, deep vein thrombosis; CUS, compressive venous ultrasound. 
cold/atrophic usually associated with a combination of autonomic, vasomotor and sensation alterations, such as pain, different temperature of the extremities, edema, skin discoloration, impaired hair and nails growth, hyperhidrosis, skin/muscular/bone atrophy, involuntary movements, tremors, muscle spasms, asthenia, paresis/pseudo-paresis, hyperesthesia, hyperpathia, hyperalgia.

In 1994 diagnostic criteria have been proposed by the International Association for the Study of Pain (IASP) ${ }^{29}$ then reviewed in the following years and subsequently replaced by the Budapest criteria (sensitivity $99 \%$, specificity $68 \%$ ). ${ }^{30}$

\section{Lymphatic obstruction}

\section{Lymphedema}

Lymphedema is usually localized to upper or lower extremities due to impaired local lymphatic drainage ${ }^{31}$ with a fluid overload and increased interstitial lymphatic volume and is very common after breast cancer surgery. ${ }^{32}$ Symptoms include non-painful swelling and a feeling of heaviness that worsens with warm temperature, pitting edema followed by subcutaneous fibrosis and hard edema, skin changes and venous stasis pigmentation (brownish skin discoloration), hyperkeratosis, papillomatosis. Skin may also crack and lymph leak, leaving the skin vulnerable to bacterial infection and worsening the lymphatic drainage, thus creating a vicious circle.

\section{Diagnosis}

The diagnosis is based on bilateral assessment of leg swelling through the Leg-O-Meter, ${ }^{33}$ ultrasound, lymphoscintigraphy, computed tomography (CT) and magnetic resonance imaging (MRI). ${ }^{31}$

\section{Treatment}

The aim is to reduce the progression of the disease, the size of the affected extremities, the symptoms and the risk of infection. ${ }^{31}$

Conservative: skin care, lymph drainage, compressive stocks.

Drugs: flavonoids (effective in the venous stasis)

Surgery: de-bulking or bypass procedures should be considered only if other therapies have shown not to be effective and if the venous system is patent, continent and the lymphatic system is functioning properly.

\section{Classification of lymphedema}

Primary lymphedema: caused by congenital abnormalities of lymphatic structures.
Secondary lymphedema: due to many causes, such as malignancies, traumas and infections.

\section{Malignancies}

Malignancies include: i) pelvic cancers causing local bulky; ii) metastatic infiltration: melanoma, ${ }^{34}$ prostatic, testicular ${ }^{35}$ or penile cancer, ${ }^{36}$ gynecologic tumors ${ }^{37}$ or intestinal lymphomas; iii) vascular malignancies: angiosarcoma, often secondary to chronic post- mastectomy lymphedema, also known as Stewart-Trevers syndrome. ${ }^{38}$

\section{Traumas}

Lymphedema can occur after local mechanic traumas (domestic or road accidents, burns, etc.) or can be secondary to: i) general surgery, especially after extensive lymph nodes excision (pelvic or paraaortic $)^{37}$ and actinic fibrosis post- radiotherapy; ii) vascular surgery (venous or arterial): lymphedema could be present in more than $60 \%$ of people who underwent surgery for varices, both because the lymphatic impairment is common in venous insufficiency but also because of a direct lesion of lymphatic ducts; $; 9$ iii) Baker's cyst rupture; ${ }^{40}$ iv) podoconiosis (non-filarial endemic elephantiasis) is common in tropical areas of Africa and India, usually in people walking with bare foot. It is related to repeated skin micro-traumatisms by alkaline irritants in the soil (silica or beryllium). ${ }^{41}$

\section{Soft tissues infection}

This condition might present in several different ways, ranging from very mild to severe and fatal infection. ${ }^{42,43}$ The severity mainly depends on: i) depth of the affected tissue; ii) host immune system; iii) pathogen responsible of the infection.

The empiric antibiotic therapy for mild to moderate infections should be: penicillin, cephalosporins (I-II generations), macrolides, clindamycin (A-I). Community-acquired methicillin resistant Staphylococcus aureus (MRSA) might often be susceptible to clindamycin or co-trimoxazole and fluoroquinolones; instead community-acquired MRSA infections might be resistant to clindamycin and should be treated with vancomycin, linezolid, daptomycin or telavancin.

In severe infections and in hospital-acquired MRSA that are usually multi-resistant to erythromycin, clindamycin and fluoroquinolones, the first-line empiric therapy includes vancomycin, teicoplanin, linezolid, daptomycin (A-I), tigecycline. ${ }^{44}$ 


\section{Impetigo and cutaneous abscesses}

Usually painful, fluctuant, erythematous lesion with a pustule on the top. It is often poly-microbial and may necessitate an incision and pus drainage (A-I).

\section{Erysipelas}

Infection of the upper dermis and lymphatic vessels, usually caused by $\beta$-hemolytic Streptococcus. The diagnosis is made by clinical finding of a wellcircumscribed erythematous lesion with a typical raised edge.

\section{Cellulitis}

The lower dermis and subcutaneous fat are involved. Cellulitis is characterized by skin erythema with peau d'orange appearance (caused by lymphangitis and regional lymphadenopathies) and increased temperature. The pathogen might be a $\beta$-hemolytic Streptococcus, S. aureus and less frequently Pseudomonas.

\section{Necrotizing fasciitis}

It involves the muscles and fascial compartments (upper fascia and all the anatomic structures between the skin and the muscles).

Commonly secondary to superficial infections or infection deriving from skin lesions $(80 \%)$ secondary to trauma or surgery (e.g., abdominal surgery, penetrating abdominal trauma, pressure ulcers, perianal or genital abscesses, drugs injection sites).

Pathognomonic signs and symptoms are intense and continuous pain, bullous lesions, skin necrosis or pre-necrotic ecchymosis (due to obstruction of deep vessels), subcutaneous emphysema, subcutaneous tissue induration, reduced skin sensation, gangrene, skin discolorations, signs of systemic involvement despite antimicrobial therapy, such as fever, lethargy, confusion, hypotension (systemic inflammatory response syndrome criteria).

Pathogens: Streptococcus pyogenes, S. aureus, Vibrio vulnificus, Aeromonas hydrophila, anaerobic streptococci, anaerobes, intestinal flora.

The diagnosis is based on clinical features, ultrasound findings of subcutaneous thickening with hypoechoic areas of fluid and gas material; CT or MRI can also be useful to assess the extension of the lesions. The finger test consists in the incision of the lesion, aimed to obtain a sample for culture test and/or biopsy (common findings are brown exudate, increased texture of the fascia, necrotic areas).

Therapy: i) surgery: debridement; ii) antibiotics: ampicillin (A-III), ampicillin/sulbactam + clindamycin + ciprofloxacin (A-III) clindamycin and penicillin (A-II) for group A streptococci, metronidazole for anaerobes, carbapenem.

\section{Animals bites}

These lesions are usually caused by Pasteurella and Staphylococci.

Therapy: amoxicillin/clavulanic acid, fluoroquinolones + clindamycin, co-trimoxazole + clindamycin.

\section{Filariasis}

It is a helminthic infection, endemic in some tropical areas. Antibiotic therapy (doxycycline) may be helpful. ${ }^{45}$

\section{Hospitalization criteria}

Patients should be hospitalized when they are critically ill (signs of severe systemic involvement are hypotension, oliguria, tachycardia, dehydration, neurological deficit) or presenting with significantly altered blood tests (renal and/or liver failure, severe leukocytosis with neutrophilia) or when is necessary to define the etiology through aspiration, incision or drainage. Alert signs are severe pain difficult to be controlled with analgesics, skin lesions such as purple or hemorrhagic bullae, petechial lesions, skin hypoesthesia, gas content in the soft tissue.

\section{Generalized edema}

Generalized edemas include: i) heart diseases; ii) liver diseases; iii) renal diseases (Figure 3).

\section{Heart diseases}

Edema occurs when venous pressure is increased, leading to hydrostatic pressure to raise; this process may be secondary to several heart diseases. For instance, hypertensive cardiomyopathy, coronary artery disease and left sided valvulopathies tend to affect the left heart function leading to pulmonary edema, while the typical right sided failure (cor pulmonale) is characterized by peripheral edema and ascites. Nevertheless, some cardiomyopathies affect both left and right side, and sometimes the symptoms are overlapping. For instance, in pulmonary edema the increased ventricular tele-diastolic pressure is transmitted retrograde to the pulmonary veins and capillaries, raising the pulmonary pressure from normal values of $5-12 \mathrm{mmHg}$ up to $18-20 \mathrm{mmHg}$ (backward hypothesis). Similarly, in the heart failure with reduced left ventricular function, the hypoperfusion induces an increase of the sympathetic tone and renin-angiotensin-aldosterone system, rising the hydro-saline retention, vascular resistances and cardiac inotropism (forward hypothesis). However, these compensatory mechanisms become gradually ineffective to maintain the cardiac output, unless an expansion of plasmatic volume and filling 
pressures, thus contributing to the genesis of edema. $^{46,47}$

Hospitalization criteria: ${ }^{48}$

- Patients should be hospitalized if any of these conditions occur: i) severe heart failure (hypotension, worsening of renal function, confusion); ii) dyspnea at rest $\left(\mathrm{SO}_{2}<90 \%\right.$ with $\mathrm{FiO}_{2} 21 \%$; tachypnea); iii) hemodynamically unstable arrhythmias; iv) acute coronary syndrome.

- Hospitalization should also be considered in case of: i) worsening of congestive heart failure symptoms (even without dyspnea or weight gain); ii) electrolytes disturbances; iii) comorbidities (pneumonia, pulmonary embolism, diabetic ketoacidosis, transient ischemic attack/stroke); iv) multiple intracardiac devices shocks; v) first episode of heart failure.

\section{Liver diseases}

Fluid retention in liver cirrhosis is related to portal hypertension $(>12 \mathrm{mmHg}$ ) and increased pressure in the sinusoids. In the physiopathology, both the portal vein obstruction and the splanchnic vasodilation are demonstrated to be involved. In fact, the liver cirrhosis is characterized by hyperdynamic circulation, reduced vascular resistances and mean blood pressure and higher cardiac output. The underlying mechanism is a portal-systemic shunt, through collateral pathways and release of vasodilators, such as prostaglandins and nitric oxygen (endotoxins and the reduced clearance of intestinal bacteria promote the synthesis of nitric oxygen).

The decrease of blood pressure is perceived by baroceptors and triggers a neuro-hormonal response with hydro-saline retention through RAAS activation and increased sympathetic tone, even though the intravascular hypovolemia is associated with interstitial fluid expansion, increased cardiac output and extracellular sodium. Therefore, the dilutional hyponatremia is common in those cirrhotic patients with ascites, as well as decreased natriuresis and increased total sodium pool.

Similarly, the vasoconstriction with renal hypoperfusion lead to hepatorenal syndrome. ${ }^{49-51}$

\section{Renal diseases}

The nephrotic syndrome is defined by the presence of proteinuria $24 \mathrm{~h}>3-3.5 \mathrm{~g}$. Several mechanisms are involved in the pathogenesis, in particular the socalled underfilling and overflow, which are present to a certain extent in all patients and vary in different stages of the disease. The underfilling is a chronic intravascular hypovolemia, due to oncotic capillary pressure reduction. Nevertheless, the movement of fluids from the intravascular to the extravascular space

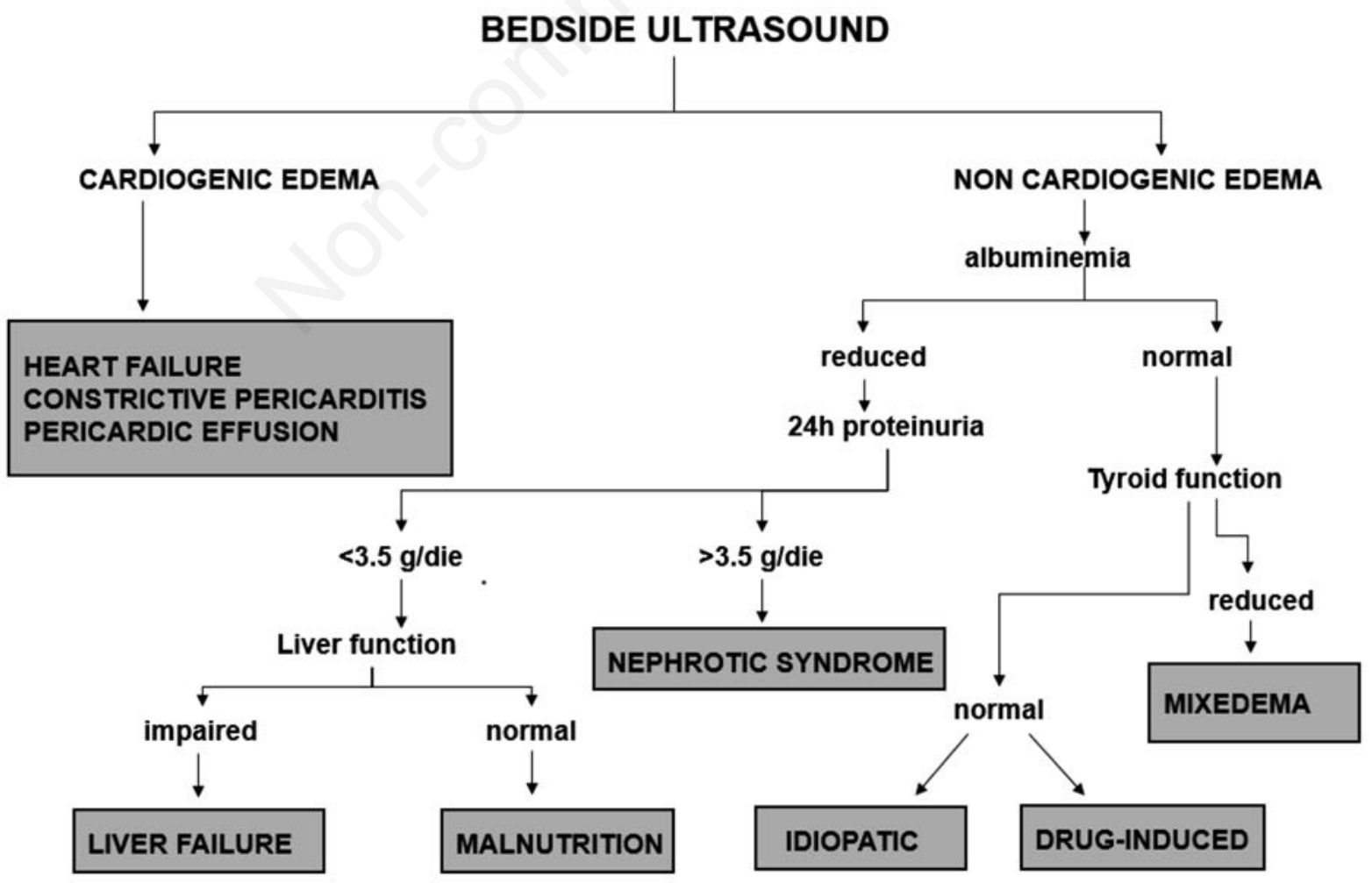

Figure 3. Approach to generalized edema. 
is mainly due to trans-capillary oncotic pressure gradient. As the plasmatic albumin is progressively reduced by urinary loss, the interstitial albumin also declines, so that the gradient does not significantly change. Therefore, the underfilling mechanism is relevant only with glomerular filtration rate $>75 \%$ of the normal value and with severe or rapid onset hypoalbuminemia. On the other hand, this mechanism is definitely not the only one involved in patients with decreased renal function by more than a half, hypertension and plasmatic albumin $>2 \mathrm{~g} / \mathrm{dL}$. In those circumstances, in fact, the hydro-saline retention is responsible for vascular overflow. Two different renal tubular dysfunctions have been identified in experimental models (increased activity of $\mathrm{Na}+\mathrm{K}+$ ATPase pump in collector ducts and resistance to atrial natriuretic peptide). In some renal progressive diseases associated with protein loss, such as membranous nephropathy and focal segmental glomerulosclerosis, there is an inflammatory cells infiltration in the tubular and interstitial space, with vasoactive factors release and hydro-saline retention secondary to tubular dysfunction and hemodynamic glomerular alterations (e.g., angiotensin-related vasoconstriction). ${ }^{52-60}$

\section{Conclusions}

In conclusion, we can summarize the following: i) edema is a very common condition to face in Internal Medicine (either in A\&E, clinic or ward) and it is the clinical presentation of several different pathologies; ii) bilateral leg swelling is often related to systemic diseases (heart, liver and/or renal affections) that should be ruled out; in the remaining cases, the most likely etiology is the venous insufficiency (in the elderly) or idiopathic edema (in young women); iii) in case of rapid onset edema, either mono- or bilateral, vein thrombosis should be investigated in first instance and, if it is not present, the clinical suspicion moves on soft tissues infections; iv) bedside ultrasound is a useful diagnostic technique in localized legs swelling (CUS, lymphedema assessment) and generalized edema (inferior vena cava ultrasound, echocardiography, pleural effusion or ascites evaluation, etc.).

\section{References}

1. Ely JW, Osheroff JA, Chambliss L, Ebell MH. Approach to leg edema of unclear etiology. J Am Board Fam Med 2006;19:148-60.

2. Yale SH, Mazza JJ. Approach to diagnosing lower extremity edema. Comp Ther 2001;27:242-52.

3. Duncan LE Jr, Liddle GW, Bartter FC, Buck K. The effect of changes in body sodium on extracellular fluid volume and aldosterone and sodium excretion by normal and edematous men. J Clin Invest 1956;35:1299.
4. Taylor AE. Capillary fluid filtration. Starling forces and lymph flow. Circ Res 1981;49:557.

5. Hommel E, Mathiesen ER, Aukland K, et al. Pathophysiological aspects of edema formation in diabetic nephropathy. Kidney Int 1990;38:1187.

6. Schrier RW. Body fluid volume regulation in health and disease: a unifying hypothesis. Ann Intern Med 1990; 113:155.

7. Henriksen JH, Bendtsen F, Gerbes AL, et al. Estimated central blood volume in cirrhosis: relationship to sympathetic nervous activity, beta-adrenergic blockade and atrial natriuretic factor. Hepatology 1992;16:1163.

8. Fernandez-Seara J, Prieto J, Quiroga J, et al. Systemic and regional hemodynamics in patients with liver cirrhosis and ascites with and without functional renal failure. Gastroenterology 1989;97:1304.

9. Pérez-Ayuso RM, Arroyo V, Camps J, et al. Evidence that renal prostaglandins are involved in renal water metabolism in cirrhosis. Kidney Int 1984;26:72.

10. Dzau VJ, Colucci WS, Hollenberg NK, et al. Relation of the renin-angiotensin-aldosterone system to clinical state in congestive heart failure. Circulation 1981;63:645.

11. Chonko AM, Bay WH, Stein JH, Ferris TF. The role of renin and aldosterone in the salt retention of edema. Am J Med 1977;63:881.

12. Crandall ED, Staub NC, Goldberg HS, et al. Recent developments in pulmonary edema. Ann Intern Med 1983;99:808.

13. Deitch EA. The management of burns. N Engl J Med 1990;323:1249.

14. Belldegrun A, Webb D, Austin HA III, et al. Effects of interleukin-2 on renal function in patients receiving immunotherapy for advanced cancer. Ann Intern Med 1987;106:817.

15. Baumgartner I, Rauh G, Pieczek A, et al. Lower-extremity edema associated with gene transfer of naked DNA encoding vascular endothelial growth factor. Ann Intern Med 2000;132:880.

16. Tan KK, Koh WP, Chao AK. Risk factors and presentation of deep venous thrombosis among Asian patients: a hospital-based case-control study in Singapore. Ann Vasc Surg 2007;21:490-5.

17. Goodacre S, Sutton AJ, Sampson FC. Meta-analysis: the value of clinical assessment in the diagnosis of deep venous thrombosis. Ann Intern Med 2005;143:129-39.

18. Wells PS, Anderson DR, Bormanis J, et al. Value of assessment of pre-test probability of deep vein thrombosis in clinical management. Lancet 1997;350:1795-98.

19. Wells PS, Owen C, Doucette S, et al. Does this patient have deep vein thrombosis? JAMA 2006;295: 199-207.

20. Wells PS, Hirsh J, Anderson DR, et al. Accuracy of clinical assessment of deep vein thrombosis. Lancet 1995;345:1326-30.

21. Institute for Clinical Systems Improvement (ICSI). Health care guideline: venous thromboembolism diagnosis and treatment. 11th ed. Bloomington, MN: ICSI; March 2011.

22. Pomero F, Dentali F, Borretta V, et al. Accuracy of emergency physician-performed ultrasonography in the diagnosis of deep vein thrombosis: a systematic review and a meta-analysis. Thromb Haemost 2013;109:137-45.

23. Othieno R, Abu Affan M, Okpo E. Home versus in-pa- 
tient treatment for deep vein thrombosis. Cochrane Database Syst Rev 2007;18:CD003076.

24. Katz ML, Comerota AJ, Kerr RP, et al. Variability of venous-hemodynamics with daily activity. J Vasc Surg 1994;19:361-5.

25. Eklöf B, Rutherford RB, Bergan JJ, et al. American Venous Forum International Ad Hoc Committee for Revision of the CEAP Classification. Revision of the CEAP classification for chronic venous disorders: consensus statement. J Vasc Surg 2004;40:1248-52.

26. Raju S, Neglén P. Clinical practice. Chronic venous insufficiency and varicose veins. NEJM 2009;360:2319-27.

27. Rutherford RB, Padberg FT, Comerota AJ et al. Venous severity scoring: an adjunct to venous outcome assessment. J Vasc Surg $2000 ; 31: 1307-12$.

28. Perez RS, Zollinger PE, Dijkstra PU et al. Evidence based guidelines for complex regional pain syndrome type 1. BMC Neurology 2010;10:20.

29. Merskey H. Classification of chronic pain: descriptions of chronic pain syndromes and definitions of pain terms. Pain Suppl 1986;3:S1-226.

30. Harden RN, Bruehl S, Perez RS, et al. Validation of proposed diagnostic criteria (the"Budapest Criteria") for complex regional pain syndrome. Pain 2010;150:268-74.

31. Tiwari A, Cheng KS, Button M, Hamilton G. Differential diagnosis, investigation, and current treatment of lower limb lymphedema. Arch Surg 2003;138:152-61

32. Mei RF, Axelrod D, Haber. J Breast -cancer-related lymphedema: information, symptoms, and risk-reduction behaviours. J Nurs Scholar 2008;40:341-8.

33. Berard A, Zuccarelli F. Test-retest reliability study of a new improved Leg-O-Meter, the Leg-O-Meter II, in patients suffering from venous insufficiency of the lower limbs. Angiology 2000;51;711-7.

34. Karakousis CP, Driscoll DL. Groin dissection in malignant melanoma. Br J Surg 1994;81:1771-4.

35. Heyn R, Raney RB Jr, Hays DM, et al. Late effects of therapy in patients with paratesticular rhabdomyosarcoma. J Clin Oncol 1992;10:614-23.

36. Okeke AA, Bates DO, Gillatt DA. Lymphedema in urological cancer. Eur Urol 2004;45:18-25.

37. Hareyama H, Ito K, Hada K, et al. Reduction/prevention of lower extremity lymphedema after pelvic and paraaortic lymphadenectomy for patients with gynecologic malignancies. Ann Surg Oncol 2012;19:268-73.

38. Shon W, Ida CM, Boland-Froemming JM, et al. Cutaneous angiosarcoma arising in massive localized lymphedema of the morbidly obese: a report of five cases and review of the literature. J Cutan Pathol 2011;38: 560-4.

39. Eickhoff JH, Engell HC. Local regulation of blood flow and the occurrence of edema after arterial reconstruction of the lower limbs. Ann Surg 1982;195:474-8.

40. Fritschy D, Fasel J, Imbert JC, et al. The popliteal cyst. Knee Surg Sports Traumatol Arthrosc 2006;14:623-8.

41. Davey G, Tekola F, Newport MJ. Podoconiosis: non-infectious geochemical elephantiasis. Trans R Soc Trop Med Hyg 2007;101:1175-80.

42. Stevens DL, Bisno AL, Chambers HF. Practice guidelines for the diagnosis and management of skin and softtissue infections. Clin Infect Dis 2005;41:1373-406.

43. Esposito S, Leone S, Noviello S, Iannello F. Analisi delle linee guida esistenti per il trattamento delle in- fezioni della cute e dei tessuti molli. Infez Med 2009; Suppl 4:58-63.

44. Liu C, Bayer A, Cosgrove SE, et al. Clinical practice guidelines by the Infectious Diseases Society of America treatment of methicillin-resistant for the Staphylococcus aureus infections in adults and children. Clin Infect Dis 2011;1-38.

45. Taylor MJ, Hoerauf A, Bockarie M. MJ. Lymphatic filariasis and onchocerciasis. Lancet 2010;376:1175-85.

46. Warren, JV, Stead, EA. Fluid dynamics in chronic congestive heart failure: An interpretation of the mechanisms producing the edema, increased plasma volume, and elevated venous pressure in certain patients with prolonged congestive failure. Arch Intern Med 1944;73:138.

47. Braunwald E, Plauth WH, Morrow AG. A method for the detection and quantification of impaired sodium excretion. Results of an oral sodium tolerance test in normal subjects and in patients with heart disease. Circulation 1965;32:223.

48. Lindenfeld J, Albert NM, Boehmer JP, et al. Comprehensive heart failure practice guideline HFSA 2010. J Cardiac Fail 2010;16:1-194.

49. Abelmann WH. Hyperdynamic circulation in cirrhosis: a historical perspective. Hepatology 1994;20:1356.

50. Fernandez-Seara J, Prieto J, Quiroga J, et al. Systemic and regional hemodynamics in patients with liver cirrhosis and ascites with and without functional renal failure. Gastroenterology 1989;97:1304.

51. Benoit JN, Granger DN. Splanchnic hemodynamics in chronic portal hypertension. Semin Liver Dis 1986;6:287.

52. Perico N, Remuzzi G. Edema of the nephrotic syndrome: the role of the atrial peptide system. Am J Kidney Dis 1993;22:355.

53. Humphreys MH. Mechanisms and management of nephrotic edema. Kidney Int 1994;45:266.

54. Koomans HA, Kortlandt W, Geers AB, et al. Lowered protein content of tissue fluid in patients with the nephrotic syndrome: observations during disease and recovery. Nephron 1985;40:391.

55. Geers AB, Koomans HA, Roos JC, et al. Functional relationships in the nephrotic syndrome. Kidney Int 1984;26:324.

56. Féraille E, Vogt B, Rousselot M, et al. Mechanism of enhanced Na-K-ATPase activity in cortical collecting duct from rats with nephrotic syndrome. J Clin Invest 1993;91:1295.

57. Rodríguez-Iturbe B, Colic D, Parra G, et al. Atrial natriuretic factor in the acute nephritic and nephrotic syndromes. Kidney Int 1990;38:512.

58. Vande Walle JG, Donckerwolcke RA, Koomans HA. Pathophysiology of edema formation in children with nephrotic syndrome not due to minimal change disease. J Am Soc Nephrol 1999;10:323.

59. Rodríguez-Iturbe B, Herrera-Acosta J, Johnson RJ. Interstitial inflammation, sodium retention, and the pathogenesis of nephrotic edema: a unifying hypothesis. Kidney Int 2002;62:1379.

60. Praga M, Borstein B, Andres A, et al. Nephrotic proteinuria without hypoalbuminemia: clinical characteristics and response to angiotensin-converting enzyme inhibition. Am J Kidney Dis 1991;17:330. 